\title{
The Invisible Hand of the Lyric Emily Dickinson's Hypermediated Manuscripts and the Debate over Genre
}

\author{
Dominique Zino
}

\begin{abstract}
Between the mid-1990s and the present, a poetics of digitization emerged around Emily Dickinson's manuscripts, performed primarily by the members of the Emily Dickinson Editorial Collective. Translating Dickinson's work across archival sources, scanned images, typographic transcripts, and coding languages has offered Dickinson's editors an escape from the determinism that accompanied the age of print and an opportunity to highlight the continuum along which the poet composed her body of work. Through multimodal, interactive exhibits, electronic editors of the Dickinson corpus often seek to demonstrate that no one medium is sufficient to represent the range of meaning implied in Dickinson's body of work. Following the treatment of Dickinson modeled by scholars such as Susan Howe, electronic editors enact a kind of lyric self-reflexivity, gradually shifting from a reflection on poetic form and metre to issues of platform and materiality. At the present moment, one in which print and electronic versions coexist alongside each other, Dickinson textual scholarship is still guided by the "invisible hand" of the lyric genre and the expectations associated with it. And yet, the more readers encounter Dickinson primarily in virtual environments, searching scanned and encoded manuscripts and interpreting them alongside typed transcriptions, the more efforts to read Dickinson in traditional generic terms will continue to be unsettled. This essay describes a lineage of textual scholars who, working with Dickinson's corpus, have made media environments into a constitutive element of genre-making.
\end{abstract}

\section{The Making of Dickinson's Visual Icons}

During the last two decades of the twentieth century, when many scholars had not yet begun to question the enduring assumption that Emily Dickinson wrote predominantly lyric poems, critics and textual editors began to give closer consideration to the material properties of Dickinson's manuscripts, decrying the use of typescript editions to interpret her collected body of work. In 1985, poet and critic Susan Howe lamented that in typographical editions fragmented visual signs and marks, the very "scrawls, turn- 
abouts, astonishments, strokes, cuts, masks" of the poet's hand, were being "banished from the body of the poem proper" in an attempt to "valorize" it (1993, 140). For Howe, the overwriting of Dickinson's scrawls between the 1890 s and the 1980s and the privileging of typography over orthography among three of her most prominent editors, Thomas Wentworth Higginson, Thomas Johnson, and Ralph Franklin, point to the patriarchal social structures that shaped the first century of Dickinson editorial scholarship. ${ }^{1}$ In response, her criticism aims to validate Dickinson's full range of poetic processes and products and to demonstrate that approaching Dickinson as a reader necessarily means approaching her as a writer. Specifically, Howe unites the roles of critic and poet through enacting the lyric genre.

Lyric poems are traditionally thought of as offering a unique encounter between a poet and the audience. Lyrics are imagined as sung in a fleeting moment, as opposed to epics, which are recited, or dramas, which are staged. ${ }^{2}$ Another feature of the lyric is self-reflexiveness. ${ }^{3}$ In My Emily Dickinson (1985), Howe both describes and enacts Dickinson's lyricism by turning her own act of literary criticism into what she calls an "archeological" quest. Howe My-nes Dickinson for meaning just as Dickinson My-ned writers such as Charlotte and Emily Brontë, George Eliot, and James Fenimore Cooper. Howe also enacts lyricism within the space of the page by creating her own "visual catastrophes", a phrase she uses to describe Dickinson's manuscript pages. For example, when presenting a reading of the poem "My Life had Stood - a Loaded Gun" (Fr764), Howe offers a representation of Dickinson's reading that appears on the page like collected layers of

1. Howe briefly recounts her exchange with Franklin in The Birth-Mark (1993): "In 1985 I wrote a letter to Ralph Franklin, the busy director of the Beinecke Rare Book and Manuscript Library at Yale University, to suggest that The Manuscript Books of Emily Dickinson show that after the ninth fascicle (about 1860) she began to break her lines with a consistency that the Johnson edition seemed to have ignored ... I received a curt letter in response. He told me the notebooks were not artistic structures and were not intended for other readers; Dickinson has a long history of sending poems to people — individual poems - that were complete, he said. My suggestion about line breaks depended upon an 'assumption' that one reads in lines; he asked, 'what happens if the form lurking in the mind is the stanza?"' (134, Howe's italics).

2. For a foundational discussion of the history of lyric forms, see Dubrow 2000.

3. Virginia Jackson argues that "self-reflexiveness is one of the central criteria of lyric discourse" $(2005,57)$. 


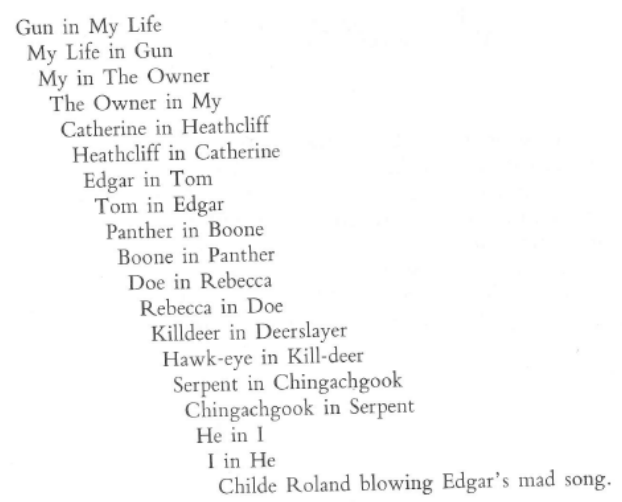

Figure 1. Page 130 from MY EMILY DICKINSON, copyright (C1985 by Susan Howe. Reprinted by permission of New Directions Publishing Corp.

sediment (or, to use a modern analogue, like lines of code), each nesting a new associative link.

The critic's attempt to envision Dickinson's reading habits turns Howe's own manuscript into a more predominantly visual medium. The typescript page becomes a hypermediated space, or a space in which our attention is drawn to the presence of the printed typeface as a manipulable (and perhaps also manipulative) medium. Howe adopts this not only as a representational method but as a broader critical method, calling for a return to the manuscript versions of Dickinson's texts, to the scrawled verses hovering behind the printed page, to the medium within the medium. ${ }^{4}$ Readers are prompted to oscillate between seeing Dickinson's language as an imme-

4. For an extended discussion of hypermediation, see Bolter and Grusin. Their primary example of hypermediation is the "windowing" of the world through the computer interface: "The multiplicity of windows and the heterogeneity of their contents mean that the user is repeatedly brought back into contact with the interface, which she learns to read just as she would read any hypertext. She oscillates between manipulating the windows and examining their contents, just as she oscillates between looking at a hypertext as a texture of links and looking through the links to the textual units as language" $(2000,33)$. 
diate visual product, as units of language, and as a kind of hypertextual network of associations. ${ }^{5}$

The appearance of Ralph Franklin's multi-volume facsimile edition, The Manuscript Books of Emily Dickinson (1980) also made possible a broader awareness of variations within particular poems that were being stifled in seemingly definitive print editions, aiding Martha Nell Smith, Jerome McGann, Sharon Cameron, Jeanne Holland, and Marta Werner, among others, as they theorized the poet's process based on the original ordering of the fascicles - the groups of poems Dickinson bound together in sewn booklets - as well as the styling of her orthography. "Dickinson's poetry was not written for a print medium, even though it was written in an age of print", McGann argues. "We must accommodate typographical conventions to her work, not the other way around" $(1993,38)$. The challenge that Howe's scholarship represented, shifting the narrative around Dickinson from one of isolation to one of connection, from the lyric tradition of what was heard to what is seen, was realized in 1995, when Martha Nell Smith first published a plan for a hypermedia archive of Dickinson's work. Smith imagined a windowed screen in which various holographs of Dickinson's manuscript pages could appear at once, searchable by a variety of textual features, with many of the pieces united by the form she saw emerging in the correspondence between Emily and her sister-in-law Susan Dickinson, the letter-poem. "Since poetry originated in the writing to Susan, as did the hybrid genre, the letter-poem, and since the writings to her showcase experimentations in style, punctuation, lineation, drawings, mixing media, and calligraphic orthography, it is no surprise that [Susan] was disappointed to see conventional modes of print representation displace Dickinson's highly self-conscious, often humorous textual play", Smith observed $(1995,81)$. In short, Howe's disruption of our general complacency about reading Dickinson in typographical form motivated textual scholars to recover a sense of immediacy with Dickinson's work by drawing attention to the heavily mediated nature of the poet's process.?

5. Lev Manovich has argued that "the acceptance of hyperlinking in the 1980s can be correlated with contemporary culture's suspicion of all hierarchies, and preference for the aesthetics of collage in which radically different sources are brought together within a singular cultural object" $(2001,76)$.

6. See McGann 1993, Cameron 1993, Holland 1994, and Werner 1995.

7. Gabrielle Dean, Curator of Literary Rare Books and Manuscripts at Johns Hopkins University, outlines four realms into which material inquiries into Dickinson's processes and products have fallen: investigations that complicate the 
Between the mid-1990s and the present, a poetics of digitization has emerged around Dickinson's manuscripts, led primarily by the members of the Emily Dickinson Editorial Collective: Smith, Werner, Ellen Louise Hart, and Lara Vetter. Translating Dickinson's work across archival sources, scanned images, typographic transcripts, and coding languages offers Dickinson's editors, present and future, an escape from the determinism that accompanied the age of print and an opportunity to highlight the continuum along which Dickinson composed her body of work. Given the multimodality of online interactive exhibits, electronic editors of the Dickinson corpus often seek to demonstrate that no one medium is sufficient to represent the range of meaning implied in her body of work. Like Howe, they enact a kind of lyric self-reflexivity, yet one that shifts from a reflection on poetic form to platform, from metre to materiality. At the present moment, in which print and electronic versions coexist alongside each other, the "invisible hand" guiding Dickinson textual scholarship is still that of the enduring influence of the lyric genre, though an allegiance to the "code of hearing" and a faith in editorial accuracy seem to be giving way to Smith's early realization that in a world of digital surrogates "no one has to bear the burden of forging the perfect linguistic description of the artifact" (Smith 2002, 840, 846). As the next generation of readers encounter Dickinson primarily in virtual environments, searching scanned and encoded manuscripts and interpreting them alongside typed transcriptions, efforts to read Dickinson in traditional generic terms will continue to be unsettled.

Thirty years after Howe's important intervention, my essay describes how textual scholars have made media environments into a constitutive element of genre-making rather than an afterthought. After recounting a recent debate over the relationship between genre and medium among Dickinson scholars, I revisit Thomas Wentworth Higginson's preface to the first edition of Dickinson's Poems (1890) to demonstrate that knowledge structures in a digital age - what new media scholars call "folksonomies" - require us to conceptualize media and genre side by side. As readers encounter Dickinson's work exposed, transcribed, and described

boundaries between a completed, public text and an unfinished, private one; studies of the material features of the poet's reading and writing environment; surveys of the use of scrapbooks, albums, and commonplace books that defined the material culture of poetic production during Dickinson's lifetime; and, finally, the way virtual environments make the poet's materials more visible and readable $(2013,293,300)$. 
down to the smallest material detail in electronic environments, a next generation of Dickinson textual scholars will need to keep one eye on contextualizing and historicizing Dickinson's materials and another on understanding how generic classifications are established and how they endure.

\section{Remediation and "Regenreing"}

In October of 2007, a special issue of PMLA, "Remapping Genre" opened with an introductory statement by Wai Chee Dimock entitled "Genres as Fields of Knowledge". Dimock offered that the "recursive, heterogeneous, and heterodox process" through which genres come into existence involves continuous input from other genres. She proposed the coinage of "a somewhat awkward term, a gerund, regenreing" to emphasize the way genre change takes at least two forms; through "cumulative reuse" genres build up and accumulate layers of meaning like a palimpsest, but they also migrate to other environments and contexts. "For too long originality has been held up as the touchstone of creative authorship. . . Surely it should not be the only touchstone. Genres can do much to guide us in the opposite direction", Dimock asserts, in which the emphasis is on "the art of receiving, and affirm[ing] it as art: crafty, experimental, even risk-taking" (2007, 1380). ${ }^{8}$ This focus on receiving, Dimock suggests, parallels the way new media come into being, or the process media theorists Jay David Bolter and Richard Grusin have called "remediation". The logic of remediation suggests that as new technologies replace older technologies, we receive them under the assumption that they will repair a lack of immediacy and transparency in the older technology. Photography was thought to produce a more immediate experience than painting, film a more immediate experience than photography, television than film, and virtual reality than television (Bolter and Grusin, 2000, 60). The desire by textual editors, especially over the last three decades, to peel back the typescript Dickinson poem to "reveal" the medium within the medium makes the changing presentation of Emily Dickinson's body of work an ideal case study of remediation. And, though it is tempting to argue otherwise, remediation is never a neutral process.

8. Dimock draws her comment about the overdetermination of originality as a hallmark of creativity from Peter Stallybrass's remarks in the same journal issue. 
Material culture scholars point out that the types of paper on which Dickinson wrote situate her within historical and cultural networks (Socarides 2012). Following this literal paper trail is a way of showing how the poet "recognize[d], respond[ed] to, act[ed] meaningfully and consequentially within, and thus participat[ed] in the reproduction of, recurring situations", which is exactly how genre theorists define participation in genre systems (BAwARSHI and REIFF 2010, 212). In other words, the remediation of Dickinson's oeuvre has long happened as part of conversations about "regenreing". Dickinson's habits of composing on borrowed or used materials become part of the poet's response to social expectations, motives, relationships between readers and writers (BAwARsH and ReIfF 2010, 13). In other words, tangible, print media implicates its users in networks of social exchange that provoke types of textual reproduction. Whether Dickinson writes on fine stationary paper or chocolate candy wrappers, media, particularly when understood as part of a process of change, heighten readers' and editors' awareness of genre and force them to engage with regenreing. When moving from close reading handwritten letters, loose pages, and fascicles to the first typescript edition in the 1890s, and when moving again from typescript editions to electronic archives in the 1990s, the transformation of textual representation through shifting forms of media also transforms critics' and readers' ideas about what counts as a generic marker.

Limited attention has been given to analyzing how receiving Dickinson's materials in electronic environments changes the way we understand and use genre systems. Among the members of the Dickinson Editorial Collective, which has, since the 1990s, shouldered the majority of the electronic editing of Dickinson's texts, Marta Werner has framed her textual scholarship as an effort to "un-edit" Dickinson, arguing that facsimiles of Dickinson's manuscripts allow scholars to imagine the possibility of presenting Dickinson's textual artifacts to an audience with "a minimum of interference”. In her printed monograph, Emily Dickinson's Open Folios (1996) — a facsimile edition of the late body of letters and fragments exchanged between Dickinson and possible lover, Judge Otis Lord - and in the corresponding digital installation hosted on the Emily Dickinson Archives, "Ravished Slates", Werner aims to subvert the limitations of typographic text while also reminding readers and viewers of the presence of the original materials; for instance, she uses a detailed notational system to record the catalog number of each leaf and sheet, occasionally adding the word "verso" to indicate when Dickinson was writing on the back of a leaf of stationery or other surface ("Lost Events"). 
More recently, the method of accommodating typographical conventions to Dickinson's work has informed The Gorgeous Nothings (2013), edited by Werner and textile artist Jen Bervin, with a preface by Howe. This edition of the series of verses and fragments written on envelopes and other "scraps" places pristine facsimiles in the midst of generous portions of white space, sometimes using only a tenth of the full nine-inch by twelve-inch page to display a two-inch fragment. Typographical transcriptions created in Adobe InDesign do not present parallel lines of text in stanzas but, instead, transcribe each letter as it would have appeared on the page, complete with all aberrant marks, and placed within a boarder that matches the asymmetrical outlines and ripped edges of the paper scraps on which the words were found. This approach reflects "[the editors'] belief that Dickinson's manuscript is the primary space to read her work and is the highest authority on all questions" and "gesture[s] back to the "bright Orthography' of Dickinson's manuscripts" (Werner and Bervin 2013, 16 note 14). In this case, the immediacy and self-reflexiveness that characterize lyric discourse merge with careful practices of hypermediation to underline the constructed nature of a transcription left floating in the vast open space of a 12 x 15 inch page. The editors' sensitivity to the uses of the blank page and the process of working across mediums and across modes of transcription suggests the "double logic" that drives acts of remediation: such textual editing involves highlighting and multiplying acts of mediation in order to generate "a feeling of fullness, a satiety of experience, which can be taken as reality" (Bolter and Grusin 2000, 53).

In 2005, twenty years after Howe's My Emily Dickinson was first published, Virginia Jackson pointed to Howe's and Werner's editorial strategies as part of a more pervasive phenomenon around interpreting Dickinson. Jackson called this trend "lyric reading". Rather than insisting, with McGann, that a print tradition must be accommodated to Dickinson's orthography, Jackson argued that a codex print tradition is what made possible the enduring scholarly assumption that Dickinson was writing "lyric poems". Dickinson's texts have been framed since the publication of the first edition of her poems in 1890 as objects that point to a narrative of "individual creation or individual reception", as both sceneless and isolated, Jackson claims. Contemporary textual editors who attempt to "rescue", "release", and "liberate" a work that is difficult to categorize by implicitly reading it as a "lyric" fall into a long line of late-nineteenth- and twentieth-century editors of Dickinson who have idealized lyric poetry as a "temporally self-present or unmediated" genre (9). Such rescue efforts, Jackson argues, ironically doom it to 
a perpetually uncharacterizable future: "The aspects of Dickinson's writing that do not fit into any modern model of the lyric - verse mixed with prose, lines written in variation, or lines . . . dependent on their artificial contexts - have been left to suffer under the weight of variorum editions or have been transformed into weightless, digitized images of fading manuscript made possible by invisible hands" $(2005,13) .^{9}$ According to Jackson, when we read Dickinson, we read not only what does or does not appear on the printed page or screen; we read through an entire history of printing. At the same time, we do not automatically bring new generic assumptions to a text simply because we digitize it.

Yet if textual scholars who have contributed to creating a poetics of digitization around Dickinson's remediated visual icons have perhaps underestimated the historicized impact of genre on our reading practices, Jackson's argument in 2005 risked overdetermining it:

The fact that Werner's immensely technologically accomplished representation of the unprinted Dickinson ends in a fundamental form of lyric reading demonstrates that reading's dependence on the cultural mediation of any medium - whether print, pixels, or skywriting. As long as there is a cultural consensus that Dickinson wrote poems and as long as poems are considered essentially lyric and as long as the cultural mediation of lyrics is primarily interpretive and largely academic - indeed, as long as lyrics need to be interpreted in order to be lyrics - then the media of Dickinson's publication will not change the message [. . .] It is not the medium but the genre that determines the message. (2005, 52, italics in original)

More than a decade after Jackson made this argument, and many digital Dickinson archives later, one must wonder whether encountering a poem in a new media environment can eventually undermine the tendency to label a poem as "essentially lyric". In the early 2000s, it may not have been

9. The notion of delivering a manuscript through "invisible hands" might also be understood as a corollary of what digital humanist Matthew Kirschenbaum calls the "haptic fallacy", "the belief that electronic objects are immaterial simply because we cannot reach out and touch them" ("Materiality and Matter and Stuff"). In general, the "double bind" Jackson sees in labeling a text as a lyric is that it demands that readers "surmis[e] associations between literal accident and figurative meaning" $(2005,67)$. 
possible for scholars to see the extent to which both media and genre may become interdependent. ${ }^{10}$ A decade after Jackson's critique of Werner's project, we are better poised to study how the lyric tradition might be both reinforced and disrupted by multi-faceted digital representations and connections across manuscripts. The last few decades of digital editing of Dickinson's papers reveal the law of remediation at work: the desire to achieve some intimacy with the original documents will drive the use of the current technology and the development of new tools. Working with digital surrogates - the shift from what Smith calls preparing to hear to preparing to see - relieves scholars from starting critical inquiries with the assumption that Dickinson wrote lyric poems. Jackson's argument marks a turning point, an implicit challenge, as I see it, to electronic editors to make visible the presence of remediation in the editorial process. By heightening readers' attention to the cumulative impact of media environments on interpretive practices, editors of digital editions have the potential to redefine an understanding of lyrics as not immediately self-present but as constructed through multiple mediations and exchanges.

In the electronic exhibit Radical Scatters: Emily Dickinson's Late Fragments and Related Texts, 1870-1886, first operated through the University of Michigan (1999-2007) and currently run through the University of Nebraska-Lincoln, Werner compiled Dickinson's textual fragments from six formal archives and a private collection. ${ }^{11}$ Werner and the Dickinson Editorial Collective have come to call the transformation of material objects into electronic objects "diplomatic transcripts". The combined use of print technology, MacroMedia Freehand, and Adobe Photoshop to represent various aspects of Dickinson's handwriting in Radical Scatters, Werner notes, provides "a partial escape from print, from the logic of iden-

10. The genre of the lyric may be a fiction, as Jackson expertly shows, but the fiction guiding lyric reading is akin to the rhetoric around digitization and modes of digital markup. Even Jackson cannot resist equating digital editing to a mystical process in which imagined pixels on a screen are a step away from "skywriting". Her use of the phrase "invisible hand" highlights what she takes to be the selfeffacing, mysterious, or undetermined nature of the role of the digital editor.

11. These include Amherst College Library (29 fragments), Houghton Library (12), Boston Public Library (6), New York Public Library (1), Yale University Library (1), Princeton University Library (1), The Rosenbach Museum and Library (1), the Jones Library, Inc. (1) — and one fragment from the private collection of Donald Oresman . 


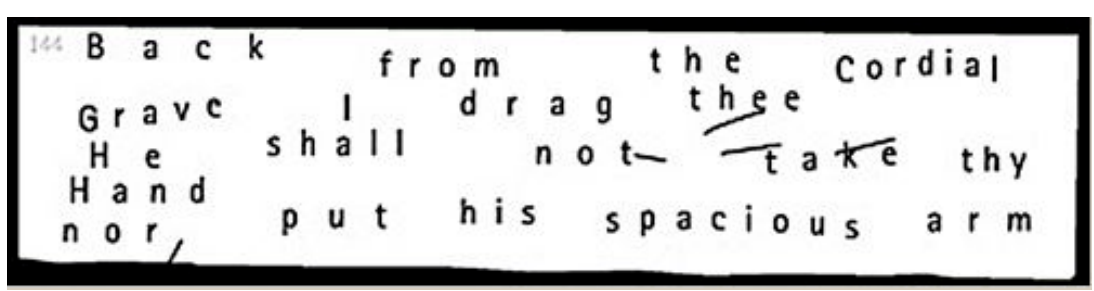

Figure 2. A diplomatic transcription of manuscript A 144, a fragment written on both sides of a scrap of paper that may or may not belong with other fragments in the collection. (c) The University of Nebraska-Lincoln.

tity and fixity". Diplomatic transcriptions, she explains, are intended to highlight the work of multiple editorial hands:

We [Werner and Patrick Bryant, her former graduate assistant at Georgia State] began by calling a facsimile of the manuscript to be translated to the screen and tracing its contours, seams, instresses to create a frame and body for the text. Next, we typed directly over the facsimile, reporting as precisely as possible the orthography, punctuation, line breaks, and spaces between letters and words. Though only three fonts were used to distinguish among three constantly recurring scriptural styles (rough-copy; intermediate-copy; fair-copy hand), font sizes were varied according to the size of the handwriting on the individual documents [. . .] Marks made on the transcripts by copyists, editors, cataloguers, and others appear when still discernible in grey italic font and in shadow. ("A Woe of Ecstasy")

While creating the diplomatic transcription, in order to render the fullest possible experience of the primary source material, the original document itself must be overwritten by a new set of marks and tracings. Digital manipulations of the text necessarily become more primary in the effort to "restore" a fuller sense of materiality to the host object: "When a diplomatic transcription is complete, it covers the image of the manuscript, concealing and even appearing to master it. Only, however, for an instant. For the precise moment when the facsimile is obscured by the transcript, a kind of 'kinetic occlusion' occurs: the transcript is 'lifted off' and placed behind the facsimile, effecting a sudden restoration of the visible over the legible" ("A Woe of Ecstasy"). The anxiety around the difference between the visible and the legible that began with Howe's representation of Dick- 
inson's text finds an expression a quarter of a century later in Werner's poetic description of the work of media in electronic environments.

This engagement with the text leads Werner, as editor, to draw certain conclusions about genre. She rejects the status of the fragments as "aphorisms" and "epigrams" ("Most Arrows") without connections to or repetitions across other poems or letters. Insisting upon the unclassifiable status of the fragments, the Radical Scatters archive invents new generic classifications, dividing fragments into "core texts" and "trace fragments". Core texts have been assigned composition dates after 1870 and are "materially discrete". Trace fragments "are caught between their attraction to specific bounded texts and their resistance to incorporation ... like leitmotifs, the fragments both influence the modalities of the compositions in which they momentarily take asylum and carry those leitmotifs beyond the finished composition into another space and time" ("A Woe of Ecstasy"). Each core fragment is contextualized through an impressive range of data: physical description, the original collection where the fragment was found, a transmission history (some verifiable, some more speculative), a publication history that notes how twentieth-century editors (i.e., JoHnson and FRANKLIN) numbered and dated the fragments, and a paragraph of commentary about relationships between the texts in which the fragments appear and their variant forms. Werner's unique organizational contribution is twofold - a system that would be impossible to replicate in a print edition. First, she arranges these fragments into "constellations" that indicate the various ways each fragment appears as a "trace" in other texts that were penned either before or after the fragment was composed, all hyperlinked across the collection so that one can move back and forth between the pages that house each fragment. Sometimes two discrete fragments are linked, while other hyperlinked paths through the collection demonstrate connections between as many as six discrete texts. Radical Scatters is also meticulous in its cataloging of what earlier editors might have discarded as repetitive and unremarkable material, which provides Werner with distinct evidence about Dickinson's composing process: "just as poems often evolve out of fragments, so they often break down into fragments again, after attaining, briefly, a finished form. These fragments, while belonging to the constellation of texts that includes the poems in which they appear as traces, may also achieve the status of freestanding lyrics" (Commentary on A 313/314).

Sometimes this process of remediation leads Werner to declare that Dickinson's late fragments are "extrageneric" (the kind of lyric reading of Dickinson with which Jackson takes issue). But Werner also notes that 
the existence of fragments across both prose and verse "suggests the need to reimagine the boundaries between 'poems,' 'letters,' 'drafts,' and 'fragments" ("A Woe of Ecstasy"). ${ }^{12}$ Werner argues that a material "is often a metaphorical as well as an actual container for thoughts - an envelope shaped like a bird carries a text about flight; an envelope seal becomes the space for a meditation on secrecy; the two sides of a document are inscribed with rhyming texts; a torn edge corresponds to a textual verge, etc. - maintaining the integrity of the physical document facilitates further investigation into the relationship between Dickinson's medium and her messages" ("Navigating in the Archive: Orientation, Disorientation, Reorientation"). Genre theorist Charles Bazerman has contended that we construct our perception of "new communicative domains" using forms we already know as a starting point (BAwARshi and ReIfF 2010, 160). Thus, importantly, while the lyric is Werner's way into the database, it is not the preordained end point of the electronic editing of Dickinson's poems. If, as Jackson contends, a print tradition has long dictated the ways readers would read Dickinson's "lyric poems", how will the predominance of digital editions in the 21st-century impact the way future editors and readers understand the genres in which she wrote?

\section{Emergent Materialities, Emergent Genres: Lyric Folksonomies}

According to Jackson, what differentiates her historicization of the lyric genre from other critics' automatic inscription of Dickinson's poems within the lyric tradition is the fact that the latter ascribes to a notion of genre as "medium" while she understands genre as "work" $(2005,46) .{ }^{13}$ Yet for

12. More recently, Werner has also classified the poems Dickinson wrote on used envelopes as "limit texts", comparing them to "John Clare's asylum writings, Friedrich Hölderlin's most inscrutable fragments, Marcel Duchamp's late notes, C. S. Pierce's existential graphs, Antonin Artaud's 'spells'. "In such documents, that may or may not be 'art", Werner writes, "we have, on the one hand, a sense that someone is there, close to us, writing, and, on the other, that no one-that is to say, that no 'author'-is there at all. . these limit-texts, composed at the border of the unreadable, may reveal more starkly than ever the conditions of the modern manuscript and the stakes involved in encountering it" $(2011,74)$.

13. Jackson borrows this distinction from Stanley Cavell. Cavell calls for "resisting (by understanding) the temptation to think of a medium simply as a familiar material (for instance, sound, color, words), as if this were an unprejudicial 
the twenty-first century electronic editor, a text is not already a familiar material; using the medium itself is work. HTML encoding dictates how a browser displays paragraphs, fonts, or images; TEI (Textual Encoding Initiative) encoding adds descriptive or analytical meaning to a text's basic digital documentation, including details about structure, meter, bibliographic context, and manuscript details..$^{14}$

Electronic databases operate through a logic of inclusion. They are - at a basic level-collections that users can view, navigate, and search (Manovich 2000, 219). As cultural forms, Lev Manovich has noted, they privilege collecting over storytelling or narrative. Scholars of the American lyric tradition have repeated this database-narrative binary. "[Database] is the enemy of narrative, threatening it at every sentence, always shimmering, accessible, there", Ed Folsom, co-editor of the digital Walt Whitman Archive, insists. "It threatens to displace narrative, to infect and deconstruct narrative endlessly, to make it retreat behind the database or dissolve back into it, to become finally its own sprawling genre, presenting a subject as it has never been possible to present it" $(2007,1577)$. The vastness of databases makes tagging necessary, either by a single editor, multiple editors, or a series of users. When navigating a database, taxonomic structures of knowledge tied to pre-determined categories into which individual ideas or things are arranged, often become faceted systems, which are arranged through use. Faceted systems allow users to navigate a tree in which every item is "tagged" with many types of properties, which they can browse through any number of potential paths (WeINBERGER 2005, 4).

The binary between hierarchical and faceted knowledge structures mirrors critics' long struggle with genre: genres have been seen as either contingent empirical groupings or theoretical categories that draw upon some fundamental aspect of thought or expression (Culler 2014, 63). As

observation rather than one of a number of ways of taking the material of a medium, and recognizing instead that only the art can define its media" (1982, 243).

14. Jackson admits that her implicit argument throughout Dickinson's Misery is that lyrics have been remade for consumption in the classroom (2005, 262 note 32). While she does not develop this argument, others have started to do so. Lara Vetter insists that it is precisely through creating and teaching from an electronic edition of Dickinson's writings that issues of textual editing can be discussed alongside issues of writing process, presumably not only the process of the poet but her students' writing processes as well (451). For a recent illustration of this practice with poetic materials in a classroom setting, see SingER 2013. 
digital rhetorician Jeff Rice argues, "Through tagging, the digital allows us to engage in discursive encounter. We discover the encounter among tags, among users who tag, and among user and tag. Various combination schemes emerge out of these encounters, sometimes as maps, sometimes as bookmarking, sometimes in other formations" (2005). For the future of the electronic editing of Dickinson's work, this raises two issues. First, perhaps some uncertainty about materiality is not the result of "overdetermining" its influence but, as faceted knowledge structures replace hierarchical knowledge structures, the result of recognizing that the way scholars make arguments about materiality has shifted: nearly any type of material associated with an author can become a possible starting point for literary research. Faceted knowledge structures invite inquiry into the use and circulation of various types of materials without presuming any are inherently meaningful at the start. Secondly, as electronic collections grow, editors will have to decide whether they will retain the sole right to tag artifacts, or whether that right will be opened to teachers and their students, or even whole classrooms of students.

If one of the primary debates in Dickinson studies since the appearance of Franklin's facsimile edition has been whether to treat a Dickinson poem as an object that depends upon its material form or as an object from which we learn by extracting information about Dickinson's tendencies as a writer from a typographical reproduction, then at present it is nearly impossible to do Dickinson editorial scholarship without confronting that informational patterns are as essential as material forms. Objects, in order to be shared, are overwritten by information as they are coded and tagged. As N. Katherine Hayles has argued, "The materiality of an embodied text is the interaction of its physical characteristics with its signifying strategies" (2005, 104, emphasis in original). "Emergent materiality" extends beyond the physical object in order to account for physical characteristics through "the social, cultural, and technological processes that brought [the text] into being" (Hayles 2005, 103). Howe's interpretations of Dickinson's poems anticipated a concept of emergent materiality, as Howe encouraged that scholars acknowledge both the "body" of the poem - the manipulation of materials on a page - alongside the strategies of editing and interpretation signified by typographical copies of the poet's work. Hayles articulates in relation to electronic versions of texts what Howe and other scholars in the early- to mid-nineties insisted upon in relation to orthographic versions: "the disembodiment of information ... [is] not inevitable, any more than it is inevitable we continue to accept the idea that we are essentially 
informational patterns" $(1999,22)$. One of my aims in this essay has been to contextualize the balancing force of remediation that pushes scholars to return to the contextualized, material life of Dickinson's work in electronic environments.

In 1991, McGann had already begin to describe print texts as autopoietic systems, "self-generating feedback systems that cannot be separated from those who manipulate and use them" $(1991,15)$. This is even more evident in electronic environments. Lara Vetter, for example, has discussed the challenge of avoiding the "disembodiment" of information when using machine-readable TEI codes to prepare hypertext versions of Dickinson's poems. On the one hand, TEI tags often lead editors to privilege the conceptual facts of a manuscript over the material ones because the markup categories are limited when it comes to accounting for the material details of the physical artifact $(2008,442) .{ }^{15}$ On the other hand, through them we see texts not as isolated artifacts but as a systematic organization to which we are contributing. Whereas Jackson doubts that media can subvert or displace the expectations of genre, Werner's insistence that "unforeseen orders" might emerge from creating and studying the Radical Scatters archive suggests the way informational codes have the capacity "to evolve spontaneously in directions the programmer may not have anticipated" (HAyles 1999, 12).

If Werner's descriptions are still bound to the "unforeseen and anomalous orders" of the lyric, they also point the way to understanding how formal features of electronic environments will produce new classifications and become tied to new social purposes. Jackson contends that in reading a text as a lyric "we consent to take it out of circulation and, in a sense, out of generic contingency", calling the lyric the "modern antigenre . . . too formally distinct to be anything but a literary genre, and yet it pretends not to be any particular literary genre" (56). But in a digital environment the whole method for producing and delivering the lyric shifts. In an electronic archive, presenting a lyric genre does not mean taking it "out of circulation". Rather, such presentation multiplies opportunities for producing meaning (BROокE 80), making genre itself contingent on the nature of the multimedia environment.

15. While Vetter's point is to expose the pitfalls of TEI tags, not necessarily to propose a specific solution, she refers to Joseph Gringely's suggestion that "an ideal edition might not be an edition at all, but a guide to historically situated texts, a Baedeker of the diachronic publication history of individual works" $(2008,439)$. 
The next section of this essay shows that the lyric genre has in fact long depended upon a broader, multi-modal media ecosystem that went beyond the realm of print culture, or at least extended what the realm of print culture might include; medium and genre in the late nineteenth century were neither separate nor static and deterministic categories. In the final section of this piece I return to the twenty first century and to Werner's Radical Scatters to offer an example of how the emergent materialities it presents have the potential to displace assumptions about the lyric, placing textual fragments in circulation among readers and in a constellatory relation to other Dickinson texts.

\section{Mr. Higginson's Fancy}

In 1981, in a study that served as a foundation for Barton Levi St. Armand's detailed account of the broader material culture in which Dickinson produced her manuscripts (Emily Dickinson and Her Culture: The Soul's Society [1984]), St. Armand and George Monteiro published their illustrated study, “The Experienced Emblem”, which describes Dickinson's wide adaptation of the nineteenth-century popular emblem tradition. The study's primary objectives are "to identify the popular pictorial sources for an unusually large number of Dickinson's poems stretching through her entire artistic career ... to show how the knowledge of a poem's source often compels the reader to interpret that poem anew; and . . . to suggest something about the various ways in which Dickinson's imagination was fired by these often crudely overstated pictures" (1981, 267-68). ${ }^{16}$ Its method is positioned at the intersection of Dean's taxonomy of material inquiries: it offers a way to describe Dickinson's poetic production and reception in terms of materiality, highlights the material features of her reading environment and how those were transferred to her writing, places these features in the context of the popularity of the illustrated emblem book tradition, and then asks how

16. Ralph Franklin's facsimile edition of Dickinson's manuscripts was published just a few months after the study appeared, perhaps even overshadowing the potential impact of "The Experienced Emblem"; on the whole, the field of Dickinson studies would move toward textual scholarship in the 80s and 90s. A 2014 Google Scholar search yielded only four citations of "The Experienced Emblem" in The Emily Dickinson Journal, two in 1993 (one of which is St. Armand's "Emily Dickinson and The Indicator: A Transcendental Frolic" Issue 2.2 (Fall 1993), one in 2005, and one in 2006. 
physical, material emblems prompted the virtual imagery she expressed through her lexical content.

Monteiro and St. Armand describe the emblem book tradition of Dickinson's era as one that revolved around the more "simplified, appealing, and available" images in William Holmes and John Warner Barber's Emblems and Allegories (1848), a descendant of a more ornate tradition dating back to Cesare Ripa's Iconologia (1593). ${ }^{17}$ The finely etched lines rendering elaborately dressed figures amid backdrops of detailed foliage and Roman architecture in Ripa's book are replaced in the nineteenth century by a less detailed, more accessible set of images in order to make the moral message intended for its audience more transparent. When placed side by side with their precursors, the bare-boned etching and lack of varied tones are notably less sophisticated than the elaborate cross-hatching of the Ripa counterparts, which resemble history paintings more than book illustrations. A distinctly early American didacticism guides the Holmes and Barber emblem, the aim of which is clear: reduce ornamentation in and around the central figures so that they make a more direct imprint on the mind of the reader. Yet Monteiro and St. Armand also note that Holmes and Barber's emblems encompass four image-textual elements: a title, a motto (usually biblical extracts), a picture, and prose commentary that takes the shape of a "miniature sermon". By economizing Puritan dogma through the pictorial emblems and the biblical captions and moralizing explanations that accompanied them, Calvinist tenets were presented in a way that made them ripe for refiguration. In other words, Monteiro and St. Armand show, their accessibility and transparency was facilitated through hypermediation, the foregrounding of the textual and pictorial media across multiple forms. This attention to strategies of hypermediation allows the authors to

17. The edition of the Holmes and Barber's Emblems and Allegories (1848) that the authors use to demonstrate Dickinson's method of adaptation and transmutation of popular emblematics holds a prominent place in the emblem book tradition. Religious Emblems appeared in 1846, followed by Religious Allegories in 1848; the third printing combines the two into one volume. "These works were so popular that their piety leaped across the Atlantic, producing a British edition of Religious Allegories in 1854 and one of Religious Emblems in 1856. In 1860 appeared yet another version, Christian Similitudes. Still later, around 1866, all three books were brought together, along with a condensed version of [Bunyan's] Pilgrim's Progress and some other examples of inspirational literature, in a compendium volume entitled The Bible Looking-Glass, of which its publisher, Henry Howe, would later claim to have sold 120,000 copies from the "Kennebec to the Rio Grande" Monteiro and St Armand 1981, 205). 
make an argument about generic classification: emblem books are an antecedent genre that shaped Dickinson's poetic strategy. I will build on Monteiro and St. Armand's argument by demonstrating how the influence of the emblem book genre shaped the earliest reception of Dickinson's work.

Dickinson's first editors suggested the complicated ways that an awareness of the poet's media was interwoven with concerns about generic classification. The announcement that anticipated the first edition of Dickinson's poetry, "An Open Portfolio", which appeared in the Christian Union on September 25, 1890, emphasizes the unfinished character of Dickinson's "strokes" scrawled across a "sheaf" of paper, inviting readers to imagine a material text: "If we believe, with Ruskin, that, 'no beauty of execution can outweigh one grain or fragment of thought,' then we may often gain by the seclusion of the portfolio, which rests content with a first stroke and does not refine and prune away afterwards. Such a sheaf of unpublished verse lies before me ...." In the same announcement, Thomas Wentworth Higginson ushers in what became, during the six years immediately after The Poems of Emily Dickinson (1890) appeared, one of the more common comparisons across the 1890s reviews - the association with the work of William Blake:

It is believed that the thoughtful reader will find in these pages a quality more suggestive of the poetry of William Blake than of anything to be elsewhere found - flashes of wholly original and profound insight into nature and life; words and phrases exhibiting an extraordinary vividness of descriptive and imaginative power, yet often set in a seemingly whimsical or even rugged frame. They are here published as they were written, with very few and superficial changes. ... In many cases these verses will seem to the reader like poetry torn up by the roots, with rain and dew and earth still clinging to them, giving a freshness and a fragrance not otherwise to be conveyed. (Higginson 1890, III)

There was a "second coming" of Blake's work among the Pre-Raphaelites, who were committed to the materialities of expression and thus sped the progress of a renaissance of printing (MCGANN 1993, 24). The nineteenth century claimed both Blake and Dickinson as singular geniuses whose verses were interesting because they attested to the vividness of the immaterial. Yet Higginson, a devoted Ruskian Pre-Raphaelite, insisted that the poets shared a commitment not only to odd, grotesque, or spiritual themes but to the rugged materiality of textual representation. Ruskin understood, J. Hillis Miller has written, "that there is an element of writing in every 
picture. In an illuminated capital the one flows into the other. They are superimposed or interwoven. The place where one stops and the other begins can scarcely be detected" $(1992,77)$. Indeed, Judith Farr has noted that Dickinson's earliest reviewers were the first to associate the poet with visual artists as they "struggle[ed] to find suitable analogues in the visual arts to qualities they perceived in Dickinson's poetry and were unused to meeting in popular late-Victorian verse" $(1998,64) .{ }^{18}$ In the reviews that followed Higginson's preface, critics repeated the allusions to Blake's materiality and chose other media to substantiate or resist categorizations of Dickinson's content.

As I noted earlier, entering new communicative domains means constructing impressions from forms with which we are already familiar (BAzerm An 1997). In Higginson's preface, the connection drawn to Blake suggests his own exposure to Blake's illustrated books through New England Transcendentalist circles. In 1839, when Dickinson was still a small child, James John Garth Wilkinson edited an edition of Blake's Songs of Innocence and Experience that found its way to New England via Elizabeth Palmer Peabody, who sold the edition in her bookstore on West Street in Boston, where the Transcendentalist Club met. Both Emerson and Higginson reportedly owned copies. Excerpts from Blake's Poetical Sketches also appeared in the Harbinger, a weekly periodical first based at Brook Farm and later transplanted to New York City when Henry James Sr. took over as its editor. James published sets of poems from "Poetical Sketches" in two summer 1848 editions of the journal, listed as sent to him from an anonymous "London Correspondent". In fact, the correspondent was Wilkinson, his good friend, fellow Swedenborgian, and editor of the 1839 edition of Songs, who enclosed the poems with a note saying they were - in a turn of phrase very similar to those later used to describe Dickinson's work - "rough, but real gems". ${ }^{19}$ Wilkinson's preface to the 1839 edition

18. Farr offers as an example Whistler's choice of "nocturnes" to describe the artistic form of his paintings and to resist the idea that they had specific narrative content $(1998,64)$.

19. See Raymond H. Deck's series of articles from 1977-80, which trace the ways in which Wilkinson and Colman were important to bringing Blake's work into circulation in the United States at mid-century. Deck reports that To Spring, To Summer, To Autumn, and To Winter appeared with Wilkinson's note in the June 24th edition; the July 8th edition featured To the Evening Star, To Morning, and three of Blake's Songs from Poetical Sketches: How sweet I roam'd", My silks and fine array, and Love and harmony combine. In Dickinson studies, only 
of Songs records a complicated relationship to Blake's work and creates an impression of the poet that was repeated by those reading the edition at mid-century. Wilkinson's preface respects Blake's verses for capturing an innocence Wilkinson is unable to locate among his contemporaries yet severely critiques the "lowering" of spiritual phenonema in Blake's engravings, writing that Blake "delights to draw evil things and evil beings in their naked and final state ... human forms [that] are gigantic petrifications ... stony limbs, and countenances expressive of despair and stupid cruelty" (Wilkinson xix-xx qtd. in Dorfman 1969, 49). ${ }^{20}$

Despite, or perhaps because of, Wilkinson's condemnation of the pictorial aspect of Blake's visual productions, four years later Pamela Chandler Colman - the wife of the New York bookseller and publisher Samuel Colman and mother of the American landscape painter, also Samuel Coleman - began printing a series of nine of Blake's poems across four separate publications published by her husband and his co-publisher, $\mathrm{T}$. H. Carter. Casting aside "petrified despair" and "stupid cruelty" of Blake's original engravings themselves but retaining Wilkinson's overall assessment of Blake's texts as representing the innocence of eternal childhood, she created drawings from Blake's engravings largely for children's publications: Boys' and Girls' Magazine, its bound version in three volumes entitled Boys' and Girls' Library, and two gift books, The Little Keepsake for 1844 and Child's Gem for 1845. ${ }^{21}$ In the style of the emblem tradition Holmes and Barber popularized, Colman included ornamental designs

Jed Deppman has conceded that Dickinson may have encountered a few of Blake's poems in a school anthology; most other scholars argue that she probably never read him. While I do not think that Deck's research directly refutes that assumption (though it certainly unsettles it), I am arguing that the fact that Higginson owned Blake's text and read his poems in print plants the seed for the editorial connection between Dickinson and Blake. As I show in the conclusion to this essay, the connection between the poets that Higginson inaugurates in his preface to the first edition of Dickinson's poems persists over a century later in the seemingly parallel challenges twenty-first century scholars describe when adapting both poets' visual productions for electronic environments.

20. Engravings aside, Wilkinson brought to America a view of Blake as a mystical poet who had direct insight into the innocence of childhood and the powerful immateriality of the spirit.

21. Mrs. Colman was a major figure in the children's book scene and in American popular magazines in the 1830 s and 40 s, where she often commemorated the death of public figures with a poem (Dеск 1977, 15). 
from the title page and introduction of Songs, drawing them from secondhand engravings. Selected drawings of Blake's engravings eventually found their way into other publications of the Carter-Colman circle over the next decade. $^{22}$ In 1863, London art writer Alexander Gilchrist wrote The Life of William Blake, "Pictor Ignotus", a biography with selections from Blake's prose, poetry, and engravings created to refute earlier conceptions of him as mad (Dorfman 1969, 2). Thus, by the time Higginson's comparison between the work of Dickinson and Blake appeared in 1890, New England had already been exposed to Blake's emblematic style and illustrations for almost half a century.

Blake and Dickinson are brought into the same network of aesthetic relations because of the way Victorians perceived them as engaging with what Richard Sha has called the "seemingly immediate" form of the sketch. Despite their roughness and absences, visual and verbal sketches came to be valued through the logic that "less finish, less labor, and less fastidiousness ... is more aesthetic, more truthful, or, in the case of women artists, more proper.... [the sketch] must appear to resist rhetorically if it is to maintain its truthfulness, authenticity, or propriety" (SH A 1998, 3, 1). Highlighting the image of beauty and truth lying down together until they were covered in moss in I died for Beauty, but was scarce - to which Higginson and his co-editor, Mabel Loomis Todd, added the title Two Kinsmen-Higginson writes, "The conception is weird enough for William Blake, and one can no more criticize a healthy rhyme here or there than a defect of drawing in one of Blake's pictures" (Higginson 1890, 392-93). I Died for Beauty or Two Kinsmen was then repeatedly referenced during the 1890s as a poem that replicated Blake's imagery - both lexical and visual. ${ }^{23}$

22. Much children's literature of the 1830 s and 40 s was subject to codes set by the American Sunday School Union, which required authors and editors "to adhere to high standards of style and content, to have an American character, and to be morally and religiously impeccable, although nondenominational", the code directly influenced Colman's correction of Blake's illustrations. She partially covers the exposed bodies of the piper and cherub that appear on Blake's frontispiece for Songs; to the engraving from the Introduction, she adds a harp to the angel (as she does for all the angel icons that accompany her reprinting of his poems) and she adds a dog next to Blake's engraving of a shepherd because they serve "as proper introductions to a series of moral poems and tales" (DECK 1977, 16).

23. The source of the poem's guiding conceit, as Sharon Cameron has noted, is actually Elizabeth Barrett Browning's "A Vision of Poets". In the copy of Browning's Poems owned by the Dickinson family, which is where Emily probably read, 
A few months later, in December of 1890, an especially influential review appeared in the Independent: "Whatever may be said of the merits and demerits of these poems, they bear the stamp of original genius. Making allowance for a certain Emersonian diction, there is nothing like these poems in the language, unless Mr. Higginson's fancy that they resemble William Blake's will hold". ${ }^{24}$ Indeed, Higginson's fancy did hold. The comparison between Dickinson and Blake is referenced sixty-two times in the reviews of Dickinson's poetry that appear in the 1890s. ${ }^{25}$

In yet another review from 1891, one of two by reviewer John W. Chadwick, who also re-printed one of Dickinson's poems in an anthology, Chadwick pays particular attention to the layout of the first edition: "the book numbers 152 pages but it reverses to Latin rule, non multa, sed multum [not many, but much], so far as the amount of matter is concerned. There are many pieces - 123 - but many of them are but six or eight lines long, some even less; the shortest, however, filling the page as a good picture fills the wall and has no brother near the throne". The analogy to visual media to make a claim about the genre of the poetry anthology was typical of the period. This comment is followed by the comparison to Blake: "[Blake]

"A Vision of Poets", the following lines are marked in pencil: "There were poets true/ Who died for Beauty, as martyrs do/ For truth-the ends being scarcely two" (Vol. II 178). Browning's modifier, "scarcely", is retained in Dickinson's poem: "I died for Beauty-but was scarce/ Adjusted in the Tomb/ When One who died for Truth, was lain ..." (Choosing, Not Choosing 20 note 14).

24. Kinsley Twining and William Hayes Ward, "Poems by Emily Dickinson". Independent 42 (December 11, 1890), 1759. Buckingham notes that the review was believed to be written by respected critic Maurice Thompson and so held extra weight (Thompson's actual review was less enthusiastic).

25. See Buckingham entries 2, 3, 10, 12, 13, 15, 16, 17, 20, 28, 33, 44, 45, 49, 51, 52, $54,64,71,72,78,95,97,100,120,125,132,140,145,150,155,177,178,184,191$, 192, 194, 195, 202, 205, 232, 251, 254, 260, 310, 325, 333, 353, 371A, 455, 480, 489, 491, 494, 560, 569, 576, 579, 580, 587, App. E2, E3, E4 and the comparison to Blake's drawing in the Art Amateur in entry 147. The majority of these entries attribute Higginson's original comparison, and most agree, though some (especially English and Scottish reviewers) are skeptical of the link. I am not, however, making an argument about Dickinson and Blake's relative poetic talents. Instead, I am suggesting that the allusions to the materiality of their verses as sketches is something that continuously brings them into the same critical conversations over the course of nearly two centuries. The comparison between the two poets also endures into the twentieth century, surfacing in reviews by William Dean Howells, Christina Rosetti, Hart Crane, Amy Lowell, Louise Bogan, Northrop Frye, Thomas Johnson, Harold Bloom, and Camille Paglia. 
has the same feeling for values of words and same novel, sometimes startling, use of them". The combined power of minimalism and immediacy is continuously invoked through the rhetoric of the sketch, which continues to blur the lines between not only Dickinson and Blake's poems but their virtual "pictures" (Chadwick 1891, 171).

Three months later one of the most fervent defenses of Dickinson appeared in the Christian Register, written by the journal's editor, Samuel Barrows, after he received three separate letters from readers who were incensed that the Register would publish a poem as indecent as "God is a distant — stately Lover". ${ }^{26}$ Alluding to the rhetoric of immediacy and incompleteness in Higginson's characterization of Dickinson's work as part of the "poetry of the portfolio" in the announcement and preface, Barrows argues, "Her forms of expression were unconventional, not savoring the auctioneer's catalogue, like those of Walt Whitman, who shovels out of the mine the raw material for poetry, and refuses to smelt, mould, and polish it, but more, as Mr. Higginson reminds us, like the poetry of William Blake than of any to be elsewhere found" (Barrows 1891, 274). While Barrows cites Higginson directly, later reviews often lift lines - especially the connection to Blake - directly from the preface without attribution, to the extent that one wonders whether some of the reviewers had ever read Blake, or seen reproductions of his work, or simply trusted in the habit of comparing the two that Higginson had inaugurated. If the original link to Blake is intentional and purposeful on Higginson's part, establishing Dickinson as part of a class of mystical visionaries through the rhetoric of the sketch, the parallel is also repeated almost unconsciously, even hypnotically, across reviews of her work in the 1890s. Regardless, not only Blake's themes but allusions to his mediums help critics navigate the difficulty of classifying Dickinson's verses. The following 1891 Art Amateur review of the first edition, for example, is especially notable for the way it conjoins the poetry of Dickinson and Blake through allusions to materiality:

26. The poem reads, "God is a distant—stately Lover-

Woos, as He states us-by His Son-

Verily, a Vicarious Courtship-

"Miles", and "Priscilla", were such an One-

But, lest the Soul-like fair "Priscilla"

Choose the Envoy-and spurn the Groom-

Vouches, with hyperbolic archness-

"Miles", and "John Alden” were Synonyme (Fr 615). 
[Dickinson's] poems are, in relation to poetry, what the drawings of Blake are to pictorial art. Violating every canon of the mechanism and rules, they are yet its very essence and spirit. Indeed one wonders if ordinary finish and care would not have robbed them of some of their peculiar charm; for, without a doubt, the entirely original fancies they embody are so eerie and evanescent that to polish them were to lose their native beauty. Like the early woodcuts of the great emblem writers, they deal with great subjects in a way that, grotesque and imperfect though it be, realizes the force of the truth they express. ("New Publications", 1891, 157 , my italics) 27

By remediating the work of both Dickinson and Blake as part of the tradition of "the woodcuts of the great emblem writers", the reviewer capitalizes on the rhetoric of incompleteness present in many of the other reviews, while also offering a material counterpart — a virtual other — for reviewers who have not seen and may never see the original manuscripts of Blake or Dickinson and may not know their material processes. Moreover, by looking at the complexities Dickinson's first editor and critics faced when classifying her work, we can see the way the allusions to Blake were both efforts at lending a material and informational body to Dickinson's texts, while also burying them deeper in a lyric tradition. The allusion to the "roughness" of Dickinson's text mobilizes that aspect of the physicality of the original physical manuscript he had seen in the service of making both a thematic and a physical tie to Blake.

During their own lifetimes, both poets played multiple roles in relation to their work: in the case of Blake, as author, illustrator, and publisher; in Dickinson's case, as author, illustrator or collage artist, and, through her letters, as publicist. Their poems saw limited circulation and both poets expressed a certain resistance to publishing generally. Among the first round of posthumous editions, of Blake's work in the 1830s and Dickinson's in the 1890s, reproductions gave attention almost solely to the lexical and grammatical levels of their texts, rather than their layout or pictorial qualities. Furthermore, for the traditional emblematists, as the reviewer for the Art Amateur likely knew, painted images were to be added to poetry in order to imitate the large sum of spatial and temporal reality. Yet, for Blake - and,

27. Between the late eighteenth and early nineteenth centuries, wood block casts were replaced by metal plates. By the end of the next century, in the $1880 \mathrm{~s}$ and 90 s, a photograuve technique was being used in all the illustrated monthlies with the chemical bath replacing the engraver. 
I am stressing, for Dickinson - poetry and painting, word and image, or, to return to Howe's more inclusive term, "visual productions", were to be "multiplied by one another to give a product larger than the sum of the parts" (Mitchell 1983, 31). ${ }^{28}$ The possibilities for textual expression pursued by both poets, and the cultural habit of remediation expressed in the description of Dickinson's textual objects as Blakean sketches and pictures, and of both poets' work as woodcuts, display an emergent materiality that, even in the nineteenth century, led to the conflation of visual and textual material processes and the transformation of textual presence into informational pattern - conditions that textual editors have once again had to contend with as both poets' work has been transferred into digital archives. ${ }^{29}$ Even before dealing with the specific coding requirements of electronic environments, electronic editors argue that "alongside the material archive there is always the process of the virtual archive, the plane of consistency that makes possible the organization of particular objects" (Whitson and Whittaker 2013, 33). ${ }^{30}$ What the Blake/Dickinson parallel reveals is that,

28. Ronald Broglio has taken Blake's reasoning to suggest that "if objects are not themselves, or if citizens are more than themselves, they are open to a larger arena of circulation than the relational economies of capitalism and governance allow" $(2007,7)$.

29. Given that the fascicles have been the predominant source of Dickinson's work, the Dickinson archive of editions is in certain ways less complicated to keep track of than the editions of Blake's poetry; four different editions in the nineteenth century alone, edited by John Wilkinson (1839), Algernon Swinburne (1868), William Michael Rossetti (the Aldine edition, 1874), and Edwin Ellis and William Butler Yeats (1893), in addition to the selections from his poems that appeared in Alexander Gilchrist's The Life of William Blake (1863, 1880). For a full discussion of the nineteenth century's revival of Blake's work, see Dorfman 1969. With regard to the Dickinson archive, Marta Werner has been crucial in disrupting the insularity of the treatment of the fascicles as Dickinson's primary text by bringing the "Lord" letters, envelope poems, and other "radical scatters" into circulation.

30. In their discussion of the challenges of creating a digital archive of the composite imagetextual manuscripts of William Blake, Roger Whitson and Jason Whittaker note that "any Blake we encounter is articulated by the powers and potentialities of [a] virtual Blake, a Blake whose image is constructed out of a cultural apparatus forming an institutional memory" (2013, 28). Blake, like Dickinson, never produced a complete catalog of his own works, and yet past collected editions have tended to frame each author's work as a complete, established set. What the challenge of crafting an archive of Dickinson's and Blake's 
for a 19th century audience, media became a primary mark of genre. As electronic textual editing continues to unfold, these two modes of classification will become increasingly more dependent on each other.

\section{Fragments, Fractures, and the Hazards of 21st Century Interpretative Practice}

Among the many ways a curious reader might search Radical Scatters, the database of Dickinson's late fragments and related texts, one is by constellation, the groupings of between two to six different trace and variant fragments. Another is by tags related to distinct features of the manuscript: media, handwriting, paper type, the condition of the document body, whether the writing contains stray letters, numbers, underlines, or other markings, and how the writing is positioned on the paper. A viewer can search using the phrase "Dickinson's writing appears on both sides of the paper/leaf" or even look for instances when "Dickinson rotated the paper during the course of the composition of a discrete text". In addition to the organizational structure of the database, the digital interface allows viewers to approximate the experience of holding the papers up to one's nose, turning them over, or placing them side by side - an experience that is consciously computer-mediated and yet offers a virtual interaction with the documents that allows one to look even more closely than one would when handling them. What such a close encounter with a brand of paper or a poet's pencil strokes can really tell us about what a poem means is certainly worth questioning. Yet, as both Werner and Jackson would probably agree, it delivers no fewer clues than the generic label "lyric poem".

In 1995, when Martha Nell Smith first conceived of an electronic edition of Dickinson's work, she closed her plan by observing, "If we are to adopt any rule for interpretation of what the various and unpredictable yet traceably evolving Dickinson holograph marks mean, then it should be a

respective visual productions reveals is, in fact, the parallel "physical metamorphosis" their work underwent once it was publicized after their deaths (2013, 40). As Whitson and Whittaker consider the Blake archive within what they term a "wider virtual ecosystem", they invoke remediation's double logic, asking twenty-first century scholars to consider that "forms produce meaning, and . . . even a fixed text is invested with new meaning and being when the physical form through which it is presented for interpretation changes" (WHITSON AND WhitTAKer 2013, 30). 
lesbian rule like that commonly invoked in the seventeenth century. The term comes from the lesbian rule that is 'a mason's rule of lead, which could be bent to fit the curves of a molding (Aristotle Eth. Nie. 5.10.7); hence fig., a principle of judgment that is pliant and accommodating' (OED)". Over twenty years later, this rule of accommodation must be extended beyond interpreting Dickinson's handwriting to thinking more broadly about how what critics have called a "poem" comes into being, and the many lives it may lead in the process. While, as I mentioned earlier, Werner uses the term "extrageneric" to describe the fragments, the careful editorial commentary provided for each fragment and the hyperlinks to related fragments reflect a not-so-radical critical premise that building a constellation of resources around a text can reveal more than the isolated assessment of individual artifacts. We might conclude two things from examining what Radical Scatters implies about the direction of twenty-first century interpretive practice: one, in economies of electronic editing immersion in a manuscript must precede interpretation. Secondly, the processes of remediation and hypermediation displayed in a database such as Radical Scatters allow visitors to explore for themselves how generic categories such as the "lyric" cease to matter when they stray too far from accounting for material processes and products. Instead, the lyric poem must be constituted as an evolving exchange between the poet and unique readers, one in which the sentiment expressed is unfolding through the unique circumstances of the communication. Moreover, the personal expression need not be a self-contained whole; rather sentiments once written on one side of a paper dust jacket gain new purposes and spark new interlocutors when merged with an alternate line on the paper's opposite side. A multimedia, searchable electronic database allows curious readers to reconstitute something as abstract as a lyric poem as a thing once held, fastened to other things, ripped apart, folded and opened and refolded. Moreover, it allows them to reconstruct a process of cross-pollination in which genres inform and borrow from each other unapologetically.

Take, for instance, a series of fragments in Radical Scatters that are all penned around the summer of 1885, less than a year before Dickinson's death. One fragment, manuscript A 809 , composed in pencil on a dust jacket, contains two parts. The main stanza reads 


What a
Hazard
a Letter
is - When
I think of
the Hearts
it has Cleft
or healed I
almost
wince to
lift my Hand
to so much
as as [sic] a
superscription
but then we
always Ex
cept
ourselves
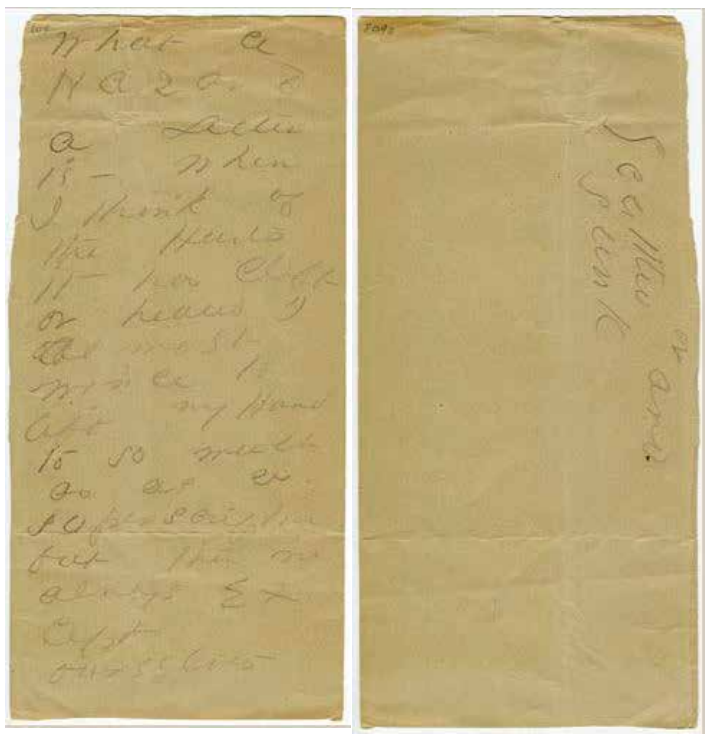

Manuscript A 809 in Radical Scatters (C) The University of Nebraska-Lincoln.

At some point while writing, Dickinson turned the paper over, rotated it ninety degrees, and wrote an alternate line as a variation of "Cleft or healed": "or Scuttled and Sunk". When seeing the lines as they were placed on the original manuscript pages below, that unit of thought appears more malleable, freed from the original lines to become the seed for other transactions.

Werner observes that this fragment may have been written while Dickinson was in physical pain or in a dark room, as her scrawls are larger and less carefully formed than in cleaner copies of other documents. The stanza itself is about the significance of individual marks on the page, and perhaps the concentration needed to scrawl a well-formed letter.

Another version of the same fragment, manuscript A 802 (below), reincorporates that fragment in a slightly different stanza. Again, form merges with meaning. The stanza - this time written in a clearer hand - is about the relationship between orthography and the danger of asserting one's presence. The speaker is almost coy: 


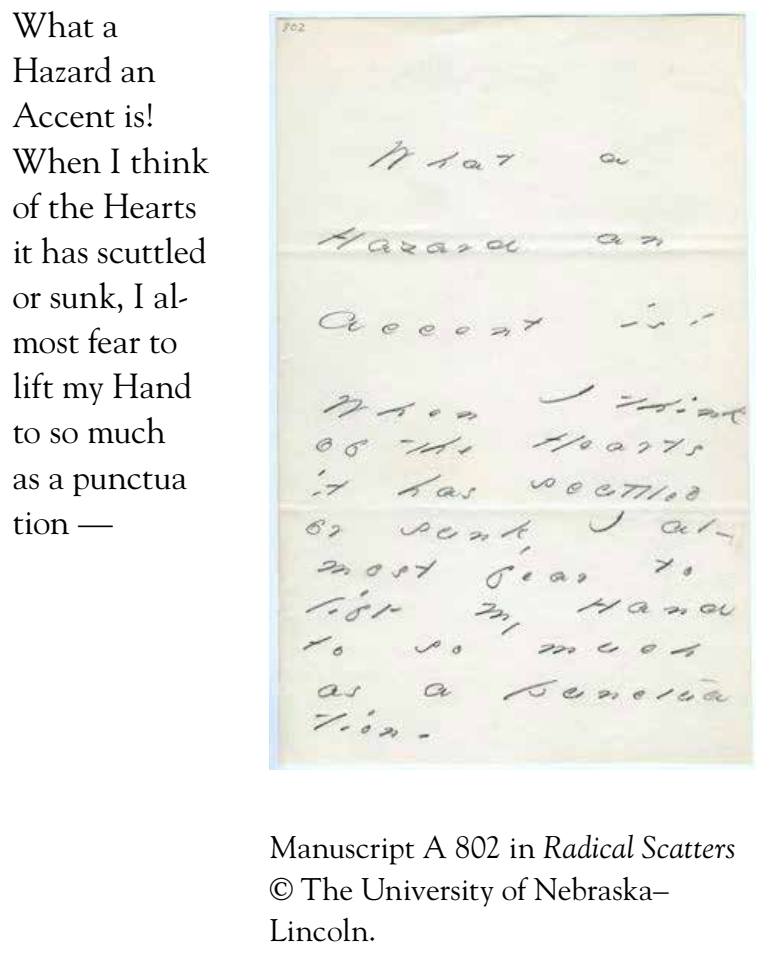

That manuscript, written on paper that was folded horizontally into thirds, perhaps to be mailed, is a variant version of the third text in this constellation, a text that may have been sent to Sara Philips Colton Gillett, longtime friend of Dickinson's niece (Susan and Austin Dickinson's daughter) Martha Dickinson Bianchi. Yet it seems insufficient to call this next text a letter. It is not personal, and Dickinson and Gillett likely had no relationship. It is signed more as a kind of keepsake for the receiver, more a courtesy than an intimate communication. ${ }^{31}$ In this third variation on the same stanza, the text reads:

31. Werner includes commentary from Thomas H. Johnson's Letters (1958) with this version: Sara Colton "did not know and never saw ED. . . The tone of this [letter], the signature, the concern with rhetorical effect, make one seriously doubt that it was in fact sent to Sara Colton. Nor was it sent to Susan Dickinson, for ED never signed notes to Sue thus. Whoever received it perhaps presented it to Sara Colton as a memento" (L 1011 n). 
What a
hazard an
Accent is!
When I think
of the Hearts
it has scuttled
or sunk,
I hardly
dare to raise
my voice
to so much
as a Salutation -
E. Dickinson-
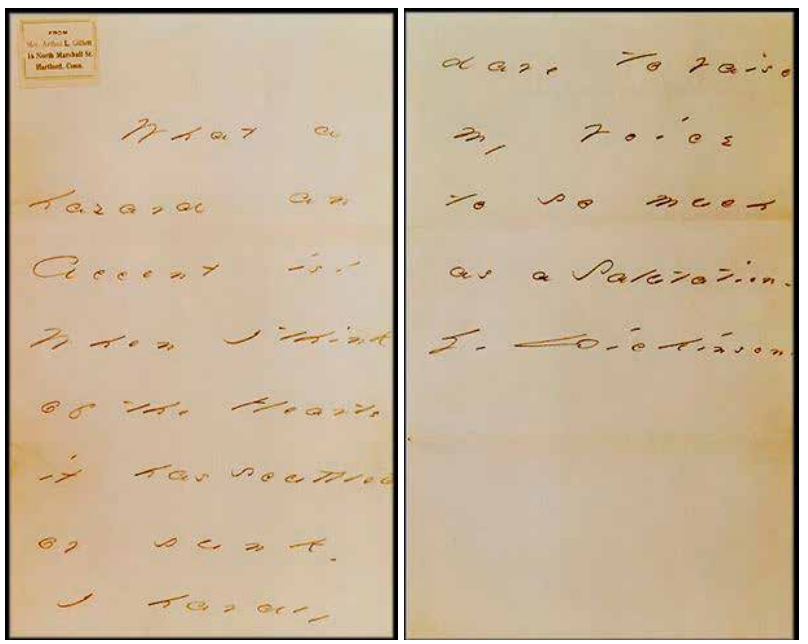

Manuscript found in the private collection of Mr. Donald Oresman in Radical Scatters (C) The University of NebraskaLincoln.

The Oresman manuscript eludes the genre of the lyric poem, the letter, and even what scholars have called the distinctly Dickinsonian genre of the "letter-poem". ${ }^{32}$ It is distant as a communication, not addressing the receiver nor making reference to any shared relationship or experience - and it is the only version of the text in which "hazard" is not capitalized. The manuscript was later attached to the front of a copy of the second volume of Letters of Emily Dickinson (1894) - more as an announcement of a poet's presence or shadow of a letter than an example of her correspondence.

The most robust version of the "What a hazard" fragment appeared as a longer letter sent to Higginson in August of 1885, upon the death of Helen Hunt Jackson, which read

32. For more on the "letter-poem", see the introduction to this exhibit in the Emily Dickinson Archives: http://archive.emilydickinson.org/letter/index.htm. 
Dear friend -

I was

unspeakably

shocked to

see this in

the Morning

Paper -

She wrote me

in Spring

that she could

not walk, but

not that she

would die -

I was sure
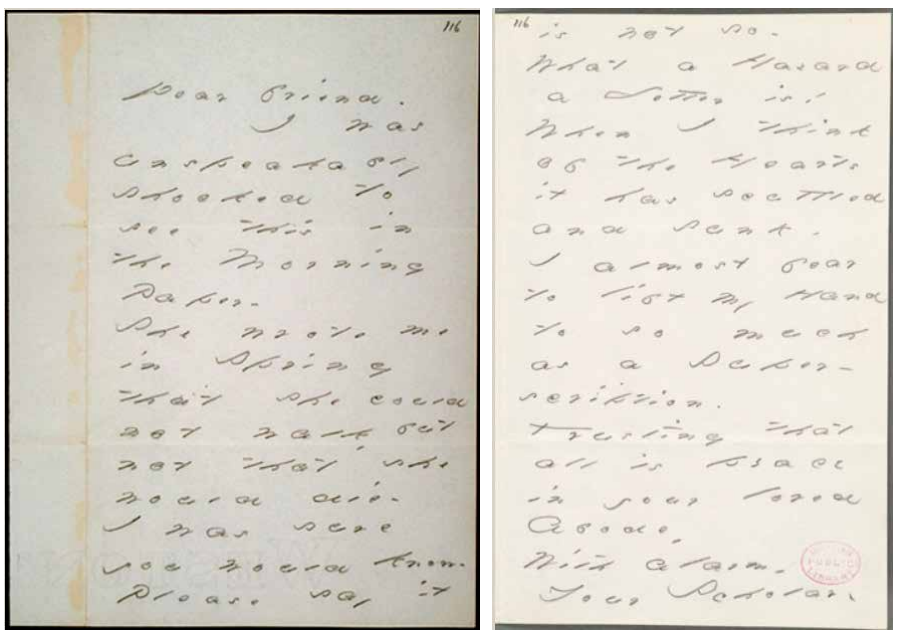

you would know -

Please say it

Manuscript BPL Higg 116 in Radical Scatters (C) The

is not so -

University of Nebraska-Lincoln

What a Hazard

a Letter is!

When I think

of the Hearts

it has scuttled

and sunk -

I almost fear

to lift my Hand

to so much

as a Super-

scription.

Trusting that

all is peace

in your loved

Abode -

With alarm -

Your Scholar -

In this version, the "letter" she references seems to connote the correspondence between Dickinson and Jackson months earlier, not the struggle to scrawl individual alphabetic characters that is implied in the rough-copy fragment (A802). The capital " $\mathrm{H}$ " and exclamation point are retained from the other versions and Dickinson never returns to the phrasing "When I 
think/ of the Hearts/ it has Cleft/ or healed" - nor to the self-conscious aside "but then we always except ourselves". The more traditional letter switches seamlessly to the more contained stanza on the second page, and then back to letter format to close the note. Given how fitting the stanza was for the occasion, it would be difficult to recognize it as a standalone piece unless one sees it in the context of the constellation through the Radical Scatters database. (While this version may have been written last because of the way it incorporates the other pieces, there is no way to know for sure, as Werner notes, the compositional order of these fragments.) Understood within a constellation, it becomes impossible to think of lyrics as self-identical standalone texts. They shift as they take on alternate lines, appear with in letters, or are re-written for strangers. As I have tried to show above, seeing the standalone fragments become other forms and take on other genres displays how the physicality and materiality of a text can be "mobilized", to use Hayles's term $(2005,103)$, in order to create meaning.

In this essay I have attempted to trace how our encounters with Dickinson's work, from the 1890s to the present moment, have been guided by our insatiable desire for immediacy, on the one hand, and by critical applications of strategies of hypermediacy and remediation, on the other. My point throughout this essay has been that the dual desire for immediacy and the strategy of hypermediacy that have defined our encounters with Dickinson's work since the 1890s reveal that critics have never really had the luxury of thinking about any material as "unprejudicial". Whether describing a poem in relation to emblem books or facsimilies in relation to encoded text, there are no pure raw materials that, in themselves, are foundational to interpreting texts - only emergent materialities. The kinship network of our interpretive experience, as Dimock reminds us, involves simultaneous processes of remediating and regenreing.

\section{Bibliography}

Barrows, Samuel J. 1891. “Emily Dickinson's Poems”. Christian Register 70 (April 30): 274. In Buckingham, 131-35

Bawa rshi, Anis S. and Mary Jo Reiff. 2010. Genre: An Introduction to History, Theory, Research, and Pedagogy. West Lafayette, IN: Parlor Press.

Bazerman, Charles. 1997. "The Life of Genre, the Life in the Classroom”. In Genre and Writing: Issues, Arguments, Alternatives. Edited by Wendy Bishop and Hans Ostrom, 19-26. Portsmouth: Boynton/Cook.

Bolter, Jay and Richard Grusin. 2000. Remediation: Understanding New Media. Cambridge, MA: MIT Press. 
Broglio, Ronald. 2007. "William Blake and the Novel Space of Revolution”, ImageTexT, Interdisciplinary Comic Studies, 3.2. http://www.english.ufledu/imagetext/ archives/v3_2/broglio/.

Brooke, Collin Gifford. 2009. Lingua Fracta: Toward a Rhetoric of New Media. Cresskill, NJ: Hampton Press.

Buckingham, Willis J., ed. 1989. Emily Dickinson's Reception in the 1890s, A Documentary History. Pittsburgh: University of Pittsburgh Press.

Cameron, Sharon. 1992. Choosing Not Choosing. Chicago: The University of Chicago Press.

CAvell, Stanley. 1982. "The Fact of Television". Daedalus 111.4: 75-96.

Chadwick, John W. 1891. "Emily Dickinson”. Unity 26 (January 22): 171. In BuckINGHAM 1989, 102-05.

Culler, Jonathan. 2014. "Lyric, History, and Genre". The Lyric Theory Reader. Edited by Virginia Jackson and Yopie Prins, 63-77. Baltimore: Johns Hopkins University Press.

Dean, Gabrielle. 2013. "On Materiality (and Virtuality)”. In Emily Dickinson in Context. Edited by Eliza Richards, 292-301. New York: Cambridge University Press.

Deск, Raymond H. 1977. "An American Original: Mrs. Colman's illustrated printings of Blake's poems, 1843-44". Blake: an illustrated quarterly 11:1: 4-18.

— 1980. "Blake's Poetical Sketches Finally Arrive in America". The Review of English Studies 31: 183-92.

Dickinson, Emily. 1890. Poems by Emily Dickinson. Edited by Thomas Wentworth Higginson and Mabel Loomis TodD. Boston: Roberts Brothers.

Dімоск, Wai Chee. 2007. "Genres as Fields of Knowledge”. PMLA 122.5: 1377-88.

Dorfman, Deborah. Blake in the Nineteenth Century. New Haven: Yale University Press, 1969.

Du brow, Heather. "Lyric Forms". In The Lyric Theory Reader, edited by Virginia Jackson and Yopie Prins, 114-28. Baltimore: Johns Hopkins University Press, 2014.

Eaves, Morris. 2006. "Crafting Editorial Settlements". Romanticism on the Net. No. 41-42. http://www.erudit.org/revue/2006/v/n442/013150ar.html.

Jackson, Virginia. 2005. Dickinson's Misery: A Theory of Lyric Reading. Princeton: Princeton University Press.

Juhasz, Suzanne. 1998. "Materiality and the Poet". The Emily Dickinson Handbook. Edited by Gudrun Grabher, Roland Habenbüchle, and Cristanne Miller, 427-39. Amherst, MA: University of Massachusetts Press.

Hayles, N. Katherine. 1999. How We Became Posthuman: Virtual Bodies in Cybernetics, Literature, and Informatics. Chicago: University of Chicago Press.

- 2005. My Mother Was a Computer: Digital Subjects and Literary Texts. Chicago: University of Chicago Press.

Higginson, Thomas Wentworth. 1890. "An Open Portfolio". Christian Union 42 (September 25), 392-93. In Buckingham 1989, 3-9.

Howe, Susan. 1985. My Emily Dickinson. Berkeley, CA: North Atlantic Books. 
1993. The Birth-Mark: unsettling the wilderness in American literary history. Middletown, CT: Wesleyan University Press.

1997. Pierce-Arrow. New York: New Directions.

Keane, Patrick J. 2008. Emily Dickinson's Approving God: Divine Design and the Problem of Suffering. Columbia, MI: University of Missouri Press.

Manovich, Lev. 2001. The Language of New Media. Cambridge, MA: The MIT Press. McGann, Jerome. 2001. Radiant textuality: literature and the world wide web. New York: Palgrave.

- 1993. Black Riders: The Visible Language of Modernism. Princeton: Princeton University Press.

- 1993. The Textual Condition. Princeton: Princeton University Press.

Miller, J. Hillis. 1992. Illustration. London: Reaktion Books.

Mitchell, WJT. 1983. William Blake's Composite Art: A Study of the Illuminated Poetry. Princeton: Princeton University Press.

—, and Mark Hansen. 2010. Critical Terms for Media Studies. Chicago: University of Chicago Press.

Monteiro, George, and Barton Levi St Armand. 1981. "The Experienced Emblem: A Study of the Poetry of Emily Dickinson". Prospects 6: 187-280.

"New Publications". 1891. Art Amateur 24 (May), 157. In Buckingh am 135, my italics.

Pepin, Susan M, M.D. 2012. “Comparison of Emily Dickinson's orbit/eyelid anatomy from the daguerreotype of 1847 and the discovered daguerreotype of two women of 1859". Dickinson Electronic Archives. http://www.emilydickinson.org/node/12. Accessed 1 July 2013.

Rice, Jeff. 2005. "21st Century Graffiti". Ctheory.net. www.ctheory.net/articles. aspx?id=484. Accessed 1 June 2014.

SHA, Richard C. 1998. The Visual and Verbal Sketch in British Romanticism. Philadelphia: University of Pennsylvania Press.

Singer, Kate. 2013. "Digital Close Reading: TEI for Teaching Poetic Vocabularies". The Journal of Interactive Technology and Pedagogy, 3. http://jitp.commons.gc.cuny. edu/digital-close-reading-tei-for-teaching-poetic-vocabularies/.

Sмiтн, Martha Nell. 1995. "The Importance of a Hypermedia Archive of Dickinson's Work”. The Emily Dickinson Journal 4.1: 75-85.

— 2002. "Computing: What Has American Literary Study to Do With It?" American Literature 74.4: 833-57.

Sмiтн, Martha Nell and Lara Vetter, with Ellen Louise Hart. 2008. Introduction to Emily Dickinson's Correspondences: A Born-Digital Textual Inquiry. The University of Virginia Press. http://rotunda.upress.virginia.edu/edc/introduction.xqy\#textual. Accessed 20 February 2016.

Socarides, Alexandra. 2012. Dickinson Unbound: Paper, Process, Poetics. New York: Oxford University Press.

Thorburn, David and Henry Jenkins. 2003. Rethinking Media Change. Cambridge, MA: MIT Press. 
Kinsley Twining and William Hayes Ward, "Poems by Emily Dickinson". Independent 42 (December 11, 1890), 1759.

Vetter, Lara. 2008. "Editing Emily Dickinson in an Electronic Environment". A Companion to Emily Dickinson, eds. Martha Nell Smith and Mary Loeffelholz. Malden, MA: Blackwell.

Werner, Marta. 1996. Emily Dickinson's Open Folios: Scenes of Reading, Surfaces of Writing. Ann Arbor, MI: University of Michigan Press.

- 2011. "Reportless Places': Facing the Modern Manuscript". Textual Cultures 6.2: $60-83$.

- 2013. "Lost Events: Toward a Poetics of Editing Emily Dickinson's Late Writings (An Illustrated Essay)". Ravished Slates: Re-visioning the "Lord Letters". Dickinson Electronic Archive. University of Nebraska-Lincoln. Accessed 28 June 2013. http://www.emilydickinson.org/ravished-slates-re-visioning-the-lord-letters.

_. 2013. "'Most Arrows': Autonomy and Intertextuality in Emily Dickinson's Late Fragments". Radical Scatters: Emily Dickinson's Late Fragments and Related Texts, 1870-1886. University of Nebraska-Lincoln. Accessed 1 December 2013. http://jetson.unl.edu:8080/cocoon/radicalscatters/mostarrows.html.

—. 2013. "'A Woe of Ecstasy': On the Electronic Editing of Emily Dickinson's Late Fragments". Radical Scatters: Emily Dickinson's Late Fragments and Related Texts, 1870-1886. University of Nebraska-Lincoln. Accessed 1 December 2013. http://jetson.unl.edu:8080/cocoon/radicalscatters/woeofecstacy.html.

Weinberger, David. 2006. "Taxonomies to Tags: From Trees to Piles of Leaves”. Last modified January 20. http://hyperorg.com/blogger/misc/taxonomies_and_tags.html. Whitson, Roger and Jason Whittaker. 2013. William Blake and the digital humanities: collaboration, participation, and social media. New York: Routledge. 